\title{
Laboratory Investigation on Mechanical Properties of Cementitious Composites with a Low Brittleness
}

\author{
Weiqun Cai, Jian Yin*, Songyun Wu, Chunning Deng, Fen Yang, Linchen Li, Jiongjun Yuan \\ College of Civil Engineering, Central South University of Forestry and Technology, Changsha, China \\ Email address: \\ 1216105420@qq.com (Weiqun Cai), 1002919857@qq.com (Jian Yin) \\ ${ }^{*}$ Corresponding author

\section{To cite this article:} \\ Weiqun Cai, Jian Yin, Songyun Wu, Chunning Deng, Fen Yang, Linchen Li, Jiongjun Yuan. Laboratory Investigation on Mechanical Properties \\ of Cementitious Composites with a Low Brittleness. International Journal of Transportation Engineering and Technology. \\ Vol. 5, No. 4, 2019, pp. 103-110. doi: 10.11648/j.ijtet.20190504.17
}

Received: November 28, 2019; Accepted: December 11, 2019; Published: December 24, 2019

\begin{abstract}
In this study, laboratory tests were conducted to investigate the mechanical behaviors of cement mortars incorporated with different admixtures, such as polypropylene fiber (PP), slag, silica fume and fly ash. Orthogonal tests were designed to evaluate the effects of the admixtures on the brittleness. The flexural strengths and the compressive-flexural ratios were selected to evaluate the brittleness. The optimal proportion can be obtained when PP content was $1.6 \mathrm{~kg} / \mathrm{m}^{3}$, and the content of fly ash, slag and silica fume was $10 \%, 20 \%$ and $3 \%$ of the cement content respectively. Using the optimal proportion, the $3 \mathrm{~d}$ flexural strength of cement mortar was $5.65 \mathrm{MPa}$, which was $19 \%$ larger than the specimens without the addition of admixtures; the compressive-flexural ratio was 4.1 , which was reduced by $19 \%$ in contrast to the control group. The flexural strength at $28 \mathrm{~d}$ was $9.04 \mathrm{MPa}$, which was $13 \%$ higher than the control group; and the compressive-flexural ratio was 4.21 , decreasing $24 \%$ compared to the control group. SEM technology was utilized to characterize the evolution of the microstructure induced by the addition of mineral admixtures and PP fiber. Results showed that mineral admixtures made the mortars denser, and the PP fiber formed a cross-linking structure, improving the brittle-resistance. The test results provided some guidance for the mixture design of pavement concrete with a high flexural strength and a low brittleness.
\end{abstract}

Keywords: Cement Mortar, Flexural Strength, Compressive-flexural Ratio, Polypropylene Fiber, Orthogonal Test

\section{Introduction}

Concrete is one of the most widely used materials for the construction of built infrastructure on a global basis. However, the tensile strength of concrete is relatively low in contrast with the compressive strength. Generally, the tensile-compressive ratio is in the range of 0.07 to 0.11 [1]. The inferior flexural behaviors adversely affect the durability, lead to very complicated modes of distress, and significantly increase the maintenance cost [1-4]. To this end, concrete with a prodigious tensile performance or brittle-resistance has been gaining rapid-growing interest as a sustainable construction material.

Fiber is widely used in concrete industry to improve the tensile performance. Lots of pioneering work has been done on the workability, mechanical behaviors and durability of the fiber-reinforced concretes [5-7]. It has been agreed that the incorporation of fiber can decrease the workability of concrete [2, 8-11]. For plastic fibers, such as polypropylene fiber and carbon fiber, the fiber shape changes during the mix and vibration process because of the interaction between fiber and mortar, resulting into worse dispersion in the fresh cement mortars or concretes. While for steel fiber, other metal fibers, the fiber shape does not change during the preparation, so that generally the workability is better than concretes incorporated with plastic fibers. Regarding to the mechanical performance, research has shown that fiber could induce a hardening effect in the post-peak stage, which playing an important impact in the flexural behavior.

The production of concrete consumes lots of energy each year. It has been reported that in 2016, more than 80 million metric tons of cement was produced in the United States, in comparison to 4200 million metric tons produced worldwide [12]. Using alternative materials to partially replace the cement is a sustainable approach to reduce the carbon dioxide emissions and is an environmental approach to 
improve the green credentials of the construction industry [13-19]. Slag, silica fume, and fly ash (FA) are the by-products and wastes of industrial production. The disposal of slag, fume and FA has become a thorny and expensive process because of the increasing strictness of environmental regulations. Nowadays, the utilization of these by-products in cement concrete industry brings tremendous environmental and economic benefits. However, many behaviors' changes due to the addition of these by-products, such as the mechanical behaviors and durability, are still not clear and must be realistically assessed.

The aforementioned review shows that fiber or the admixtures could affect some aspects of concrete properties.
However, the synergistic effect between fiber and concrete admixtures was not systematically studied. The objective of this work is not only to design a cement mortar with a high brittle-resistance, also identify the mechanism of improving the brittle-resistance by utilizing some microscopic techniques.

\section{Raw Materials and Test Methods}

\subsection{Raw Materials}

1) Cement: $\mathrm{P} \cdot \mathrm{O} 42.5$ ordinary Portland cement is adopted, and its technical parameters are shown in Table 1.

Table 1. Indexes of cement.

\begin{tabular}{|c|c|c|c|c|c|c|c|c|}
\hline $\begin{array}{l}\text { Mixed material } \\
\text { content }\end{array}$ & $\mathrm{SO}_{3}$ & $\begin{array}{l}\text { Loss of } \\
\text { burning }\end{array}$ & MgO & Setting (min) & & Specific surface area & Strength (MPa) & \\
\hline$(\%)$ & $(\%)$ & $(\%)$ & $(\%)$ & Initial setting & Finalsetting & $\left(\mathrm{m}^{2} / \mathrm{kg}\right)$ & $\begin{array}{l}\mathrm{d} 28 \mathrm{~d} \\
\text { Compressive }\end{array}$ & $\begin{array}{l}\text { 3d 28d } \\
\text { Flexural }\end{array}$ \\
\hline 13.5 & 2.41 & 3 & 3.34 & 155 & 200 & 354 & 25.352 .0 & 4.98 .9 \\
\hline
\end{tabular}

2) Physical properties of fly ash, slag and silicon fume are shown in Table 2.

Table 2. Parameters of FA, slag, and silica fume.

\begin{tabular}{|c|c|c|c|c|c|c|c|}
\hline \multirow{2}{*}{ Admixture types } & \multirow{2}{*}{$\begin{array}{l}\text { Fineness } \\
/ \%\end{array}$} & \multirow{2}{*}{$\begin{array}{l}\text { Loss of burning } \\
\%\end{array}$} & \multirow{2}{*}{$\begin{array}{l}\text { Water demand ratio } \\
\% \%\end{array}$} & \multirow{2}{*}{$\begin{array}{l}\text { Bulk density } \\
\mathrm{g} \cdot \mathrm{cm}^{-3} \\
\end{array}$} & \multirow{2}{*}{$\begin{array}{l}\text { Water content } \\
/ \%\end{array}$} & \multicolumn{2}{|c|}{ Activity index $/ \%$} \\
\hline & & & & & & $7 d$ & 28d \\
\hline Fly ash & 23.33 & 3.8 & 92 & 2.22 & 0.1 & 69 & 96 \\
\hline Slag & 6.07 & 0.9 & 80 & 2.51 & 0.1 & 95 & 98 \\
\hline Silica fume & 19 & 6 & 100 & & 0.1 & & 114 \\
\hline
\end{tabular}

3) Polypropylene fiber: its technical parameters are shown in Table 3.

Table 3. Polypropylene fiber parameters.

\begin{tabular}{llll}
\hline Diameter & Tensile strength & Density & Length \\
\hline $31 \mu \mathrm{m}$ & $\geq 700 \mathrm{MPa}$ & $0.91 \mathrm{~g} / \mathrm{cm}$ & $6 \mathrm{~mm}$ \\
\hline
\end{tabular}

4) Water: tap water was used.

5) Fine aggregate: ISO standard sand was used as the fine aggregate.

6) Superplasticizer: a polycarboxylic superplasticizer ( $\mathrm{Sp}$ ) was selected; it was classified as Type A according to ASTM C494; it has a solid content of $38 \%$ and a water reducing rate of $20 \%$.

\subsection{Test Methods}

Mechanical tests include the flexural test and compressive strength tests, which are carried out according to the test method of JTG/T 0506-2005 "Test Method for Strength of Cement Mortar (ISO Method)".

In efforts to ensure the properly fiber dispersion in cement mortars, a two-stage mixing procedure was adopted. The fiber, cement, fly ash, fume, slag, and sand were mixed first in a mixer for 3 mins, and then water and superplasticizer were added and mixed for another 2 mins. The cementitious materials include cement, FA, fume and slag. The water-binder (W-B) ratio was 0.5 for all mixtures. The mass ratio of cementitious materials to water was kept as 1:3. The specimen size for flexural test was $40 \times 40 \times 160 \mathrm{~mm}$, and the specimens after the flexural failure were used to conduct the compressive tests.

After the preparation of mortars, waterproof membranes were used to cover the surface of the fresh mortars until the specimens were demolded 24 hours after being casted. The specimens were cured at a temperature of $20 \pm 2{ }^{\circ} \mathrm{C}$ and at a relative humidity of $95 \%$. After 3 -day and 28 -day curing, the 3-day and 28-day flexural and compressive tests were conducted respectively.

\section{Results and Analysis}

\subsection{Optimization of PP Fiber Content}

Laboratory tests were designed to explore the optimum fiber content firstly. In these tests, the admixtures, including FA, fume, and slag, were not incorporated. Cement mortars are divided into six groups according to the different polypropylene fiber dosages: S1, S2, S3, S4, S5 and S6, in which $\mathrm{S} 1$ is the reference mortar group without polypropylene fiber; S2-S6 are the test groups with polypropylene fiber dosages of $0.5 \mathrm{~kg} / \mathrm{m}^{3}, 0.8 \mathrm{~kg} / \mathrm{m}^{3}, 1.2 \mathrm{~kg} / \mathrm{m}^{3}, 1.6 \mathrm{~kg} / \mathrm{m}^{3}$ and 2 $\mathrm{kg} / \mathrm{m}^{3}$, respectively. Water-binder (W-B) ratio of the specimens was kept as 0.5. Mix parameters and the 
corresponding mechanical performance are shown in Table 4.

Table 4. Mixture proportions and mechanical properties of mortars with PP fiber.

\begin{tabular}{llllllll}
\hline Number & $\begin{array}{l}\text { Cement } \\
(\mathbf{g})\end{array}$ & $\begin{array}{l}\text { W-B } \\
\text { ratio }\end{array}$ & $\begin{array}{l}\text { Sand } \\
(\mathbf{g})\end{array}$ & $\begin{array}{l}\text { PP fiber } \\
\left(\mathbf{k g} \cdot \mathbf{m}^{\mathbf{3}}\right)\end{array}$ & $\begin{array}{l}\text { Compressive strength (MPa) } \\
\mathbf{3 d ~ 2 8 d}\end{array}$ & $\begin{array}{l}\text { Flexural strength (MPa) } \\
\mathbf{3 d} \text { 28d }\end{array}$ & $\begin{array}{l}\text { Compressive-flexural ratio } \\
\text { 3d 28d }\end{array}$ \\
\hline S1 & 450 & 0.5 & 1350 & 0.0 & 24.846 .0 & 4.767 .5 & 5.216 .13 \\
S2 & 450 & 0.5 & 1350 & 0.5 & 27.545 .7 & 4.127 .6 & 6.676 .00 \\
S3 & 450 & 0.5 & 1350 & 0.8 & 25.444 .8 & 5.067 .63 & 5.025 .87 \\
S4 & 450 & 0.5 & 1350 & 1.2 & 23.842 .1 & 4.967 .71 & 4.805 .46 \\
S5 & 450 & 0.5 & 1350 & 1.6 & 22.940 .9 & 4.977 .72 & 4.615 .29 \\
S6 & 450 & 0.5 & 1350 & 2.0 & 23.039 .9 & 4.957 .39 & 4.655 .39 \\
\hline
\end{tabular}

3 days' mechanical behaviors and the compressive-flexural ratio are shown in Figures 1 and 2. Flexural strength and compressive-flexural ratio were selected as the indexes in evaluating the toughness of cement-based materials [15-17]. It can be clearly observed from Figure 1 that the compressive strength of cement mortar increased first and decreased subsequently. While for flexural strength, a minimum value was obtained when the fiber content was $0.5 \mathrm{~kg} / \mathrm{m}^{3}$ (S2). The inferior strength at this point may be ascribed to the bad dispersion of the fiber. When the fiber contents were 1.0, 1.5, and $2.0 \mathrm{~kg} / \mathrm{m} 3$, the flexural strengths were larger than the specimens without the addition of PP fiber.

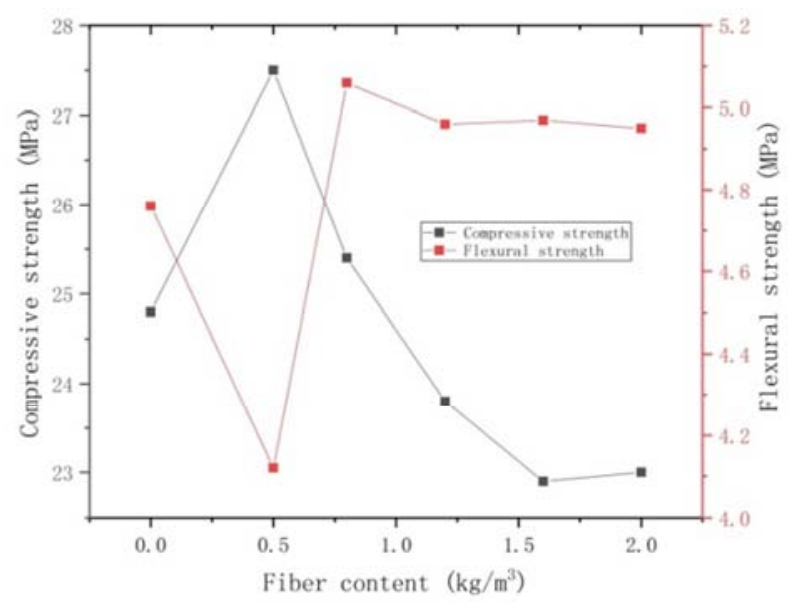

Figure 1. Compressive and flexural strength at 3 day.

When the PP fiber content was $0.5 \mathrm{~kg} / \mathrm{m}^{3}$ (S2), the compressive strength reached the maximum value, which was $11 \%$ higher than that of S1. When the content of PP fiber was larger than $0.5 \mathrm{~kg} / \mathrm{m}^{3}$, the compressive strength decreased with the increase of the content of polypropylene fiber. This is because the excessive content of fiber was not conducive to the uniform dispersion of the fiber in the cement, which produced an agglomeration phenomenon, causing local defects in the cement mortar and increasing porosity, thus degrading the mechanical performance. Compared to the compressive strength, when the PP content increased, the flexural strength almost kept stable. When the PP fiber content was $0.8 \mathrm{~kg} / \mathrm{m}^{3}(\mathrm{~S} 3)$, the flexural strength was $6 \%$ larger than $\mathrm{S} 1$. When the fiber content increased from $0.8 \mathrm{~kg} / \mathrm{m}^{3}$ to 2.0 $\mathrm{kg} / \mathrm{m}^{3}$, the strength increment was still larger than $4 \%$. The results of the compressive strength and flexural strength indicated that PP fiber played a more significant effect on the flexural strength than the compressive strength.

The development of compressive ratios was similar with the compressive strength. Maximum ratio was obtained when PP fiber content was $0.5 \mathrm{~kg} / \mathrm{m}^{3}$ (S2), indicating brittle potential of $\mathrm{S} 2$ was the largest. As the fiber content increased, the ratio decreased gradually. When the fiber content was $1.6 \mathrm{~kg} / \mathrm{m}^{3}$ (S5), compressive-flexural ratio reached the minimum value, indicating S5 presented the superior brittle-resistance.

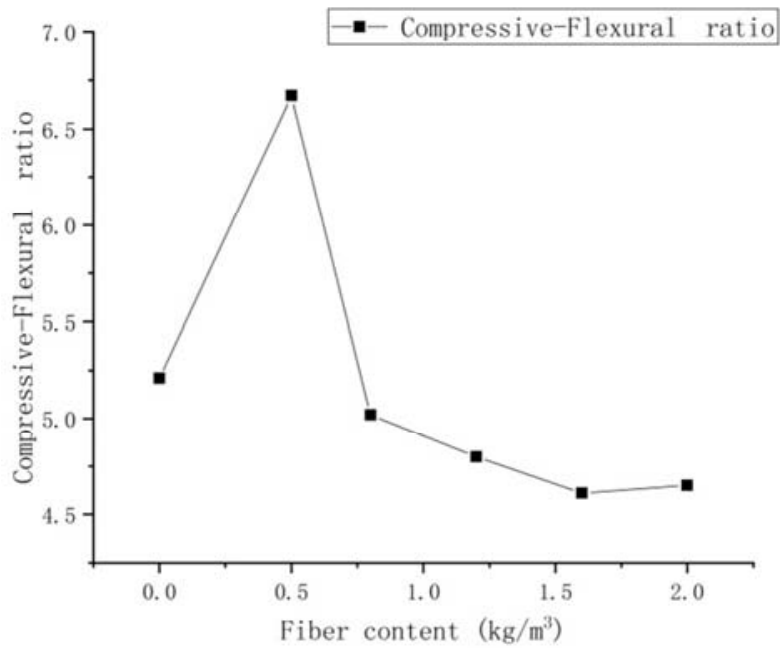

Figure 2. Compressive-flexural ratio at 3 day.

Figures 3 and 4 presented the mechanical performance at 28 day. Different from the $3 \mathrm{~d}$ performance in Figure 1, maximum compressive strength was obtained when no fiber was added, and as the fiber content increased, compressive strength decreased gradually. Meanwhile, along with the increase of fiber content, flexural strength first increased and obtained the maximum value when fiber content was $1.6 \mathrm{~kg} / \mathrm{m}^{3}$ (S5). From $1.6 \mathrm{~kg} / \mathrm{m}^{3}$ (S5) to $2.0 \mathrm{~kg} / \mathrm{m}^{3}$ (S6), the flexural strength decreased sharply. The minimum compressive-flexural ratio can be obtained when the PP content was $1.6 \mathrm{~kg} / \mathrm{m}^{3}$, at which the specimens got the best brittle-resistance. From the test results at 3 day and 28 day, it can be concluded that the optimum fiber content was $1.6 \mathrm{~kg} / \mathrm{m}^{3}$, at which the compressive-flexural ratio was the lowest, and at the same time, the flexural strength was also large enough. 


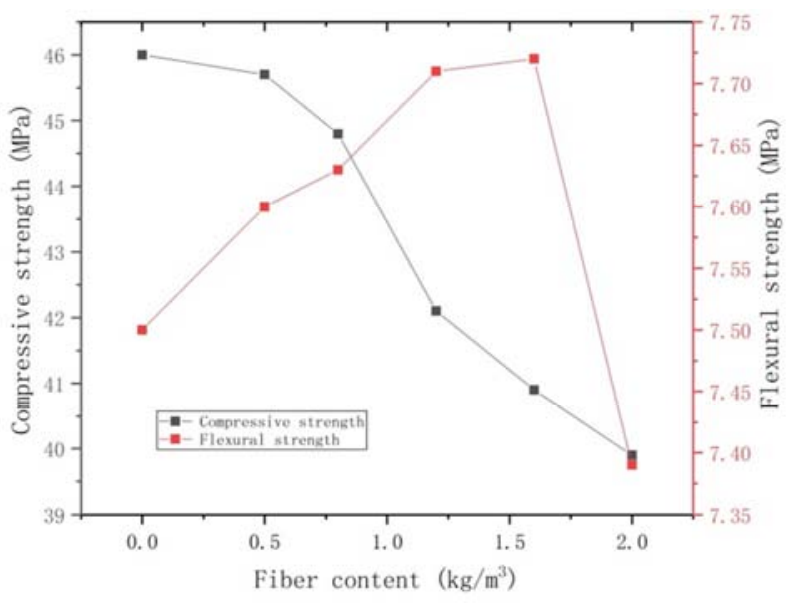

Figure 3. Compressive and flexural strength at 28 day.

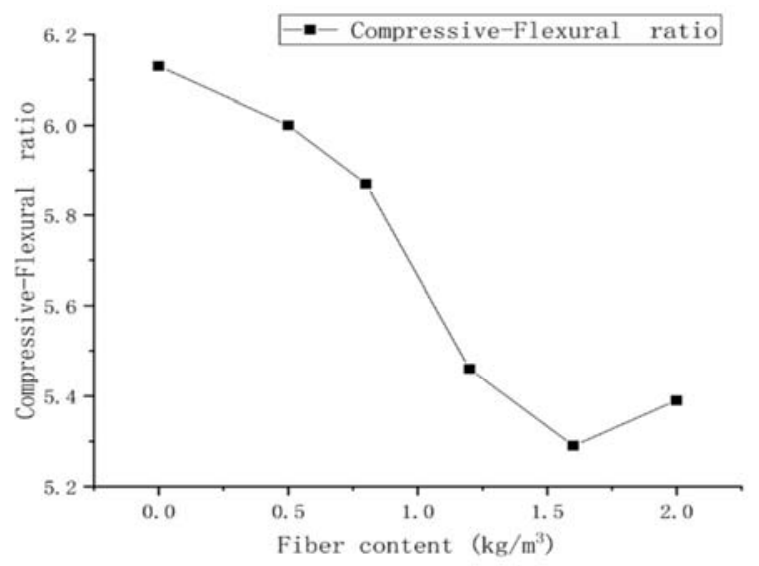

Figure 4. Compressive-flexural ratio at 28 day.

\subsection{Optimization of the Contents of Mineral Admixtures}

The PP fiber dosage $\left(1.6 \mathrm{~kg} / \mathrm{m}^{3}\right)$ was selected in this study. An orthogonal test with three factors and three levels was designed. The three factors represent FA, slag, and silicon fume, and the three levels represent replacement rates of FA, fume and slag, which can be observed in Table 5. The water reducing agent content is $0.4 \%$ for all the cement mortars, and the workability (cement matrix fluidity $>160 \mathrm{~mm}$ ) requirement is met when the water-binder ratio is 0.39 .

Table 5. Orthogonal test.

\begin{tabular}{llll}
\hline \multirow{2}{*}{ Horizontal value } & \multicolumn{3}{l}{ Major factor } \\
\cline { 2 - 4 } & Fly ash $\mathbf{A} / \%$ & Slag $\mathbf{B} / \%$ & Silica fume $\mathbf{C} / \%$ \\
\hline 1 & 10 & 10 & 1 \\
2 & 15 & 15 & 3 \\
3 & 20 & 20 & 5 \\
\hline
\end{tabular}

The orthogonal test scheme design and test result analysis are shown in Table 6 . From the $3 \mathrm{~d}$ range analysis, it can be clearly observed that: 1) when FA content was between $10 \%$ and $20 \%$, FA showed a negative correlation with the $3 \mathrm{~d}$ compressive strength and flexural strength of the cement mortars, and the compression-bending ratio decreased with the increase of FA content; 2) when the slag content was between $10 \%$ and $20 \%$, the slag had little influence on the compressive strength and flexural strength at 3 days, indicating slag played no effect on the mechanical behaviors; 3 ) when the content of silica fume was between $1 \%$ and $5 \%$, the silica fume played a significant effect on the compressive-flexural ratio, and when the content of silica fume was $3 \%$, the ratio reached the minimum value.

Table 6. Orthogonal test $3 d$ and range analysis.

\begin{tabular}{|c|c|c|c|c|c|c|c|c|c|}
\hline \multirow{2}{*}{$\begin{array}{l}\text { Number } \\
1\end{array}$} & \multirow{2}{*}{$\begin{array}{l}\mathbf{A} \\
1\end{array}$} & \multirow{2}{*}{$\begin{array}{l}\text { B } \\
1\end{array}$} & \multirow{2}{*}{$\begin{array}{l}\text { C } \\
1\end{array}$} & \multicolumn{2}{|c|}{ D/Empty train } & \multicolumn{2}{|c|}{$\begin{array}{l}\text { Compressive } \\
\text { strength }\end{array}$} & \multirow{2}{*}{$\begin{array}{l}\text { Flexural } \\
\text { strength }\end{array}$} & \multirow{2}{*}{$\begin{array}{l}\text { Compressive- } \\
\text { Flexural ratio } \\
5.46\end{array}$} \\
\hline & & & & 1 & & 31.3 & & & \\
\hline 2 & 1 & 2 & 2 & 2 & & 27.9 & & 5.84 & 4.78 \\
\hline 3 & 1 & 3 & 3 & 3 & & 26.5 & & 5.88 & 4.51 \\
\hline 4 & 2 & 1 & 2 & 3 & & 24.7 & & 5.54 & 4.46 \\
\hline 5 & 2 & 2 & 3 & 1 & & 25.6 & & 5.01 & 5.11 \\
\hline 6 & 2 & 3 & 1 & 2 & & 24.5 & & 4.84 & 5.06 \\
\hline 7 & 3 & 1 & 3 & 2 & & 23.2 & & 5.02 & 4.62 \\
\hline 8 & 3 & 2 & 1 & 3 & & 22.8 & & 4.72 & 4.83 \\
\hline 9 & 3 & 3 & 2 & 1 & & 21.0 & & 4.91 & 4.28 \\
\hline \multirow{7}{*}{$\begin{array}{l}\text { Compressive } \\
\text { strength }\end{array}$} & \multicolumn{2}{|l|}{$\mathrm{k} 1$} & 28.57 & 26.40 & & 26.20 & 25.97 & & \\
\hline & \multicolumn{2}{|l|}{$\mathrm{k} 2$} & 24.93 & 25.43 & & 24.53 & 25.20 & & \\
\hline & \multicolumn{2}{|l|}{$\mathrm{k} 3$} & 22.33 & 24.00 & & 25.10 & 24.67 & & \\
\hline & \multicolumn{2}{|c|}{$\mathrm{R}$} & 6.23 & 2.40 & & 1.67 & 1.30 & & \\
\hline & \multicolumn{2}{|c|}{ Primary and secondary order } & A & B & & $\mathrm{C}$ & $\mathrm{D}$ & & \\
\hline & \multicolumn{2}{|c|}{ Excellent level } & A1 & B1 & & $\mathrm{C} 1$ & D1 & & \\
\hline & \multicolumn{2}{|c|}{ Optimal combination 1} & $\mathrm{~A} 1 \mathrm{~B} 1 \mathrm{C} 1$ & & & & & & \\
\hline \multirow{7}{*}{ Flexural strength } & \multicolumn{2}{|c|}{$\mathrm{k} 1$} & 5.82 & 5.43 & 5.10 & 5.22 & & & \\
\hline & \multicolumn{2}{|l|}{$\mathrm{k} 2$} & 5.13 & 5.19 & 5.43 & 5.23 & & & \\
\hline & \multicolumn{2}{|l|}{ k3 } & 4.83 & 5.21 & 5.30 & 5.38 & & & \\
\hline & \multicolumn{2}{|l|}{$\mathrm{R}$} & 0.99 & 0.24 & 0.33 & 0.16 & & & \\
\hline & \multicolumn{2}{|c|}{ Primary and secondary order } & A & $\mathrm{C}$ & B & $\mathrm{D}$ & & & \\
\hline & \multicolumn{2}{|c|}{ Excellent level } & A1 & B1 & $\mathrm{C} 2$ & D3 & & & \\
\hline & \multicolumn{2}{|c|}{ Optimal combination 2} & $\mathrm{~A} 1 \mathrm{~B} 1 \mathrm{C} 2$ & & & & & & \\
\hline
\end{tabular}




\begin{tabular}{|c|c|c|c|c|c|c|c|}
\hline Number & $\mathbf{A}$ & $\mathbf{C}$ & $\mathbf{D} / \mathbf{E r}$ & train & $\begin{array}{l}\text { Compressive } \\
\text { strength }\end{array}$ & $\begin{array}{l}\text { Flexural } \\
\text { strength }\end{array}$ & $\begin{array}{l}\text { Compressive- } \\
\text { Flexural ratio }\end{array}$ \\
\hline \multirow{7}{*}{$\begin{array}{l}\text { Compressive } \\
\text {-Flexural ratio }\end{array}$} & k1 & 4.92 & 4.85 & 5.12 & 4.94 & & \\
\hline & $\mathrm{k} 2$ & 4.88 & 4.91 & 4.50 & 4.82 & & \\
\hline & k3 & 4.57 & 4.61 & 4.75 & 4.60 & & \\
\hline & $\mathrm{R}$ & 0.35 & 0.30 & 0.62 & 0.34 & & \\
\hline & Primary and secondary order & $\mathrm{C}$ & A & $\mathrm{D}$ & B & & \\
\hline & Excellent level & $\mathrm{A} 3$ & B3 & $\mathrm{C} 2$ & D3 & & \\
\hline & Optimal combination2 & $\mathrm{A} 3 \mathrm{~B} 3 \mathrm{C} 2$ & & & & & \\
\hline
\end{tabular}

Table 7 shows the orthogonal test results and the range analysis at 28 day. It can be observed that FA was the main influencing factor of flexural strength, and the content of FA should be A1 $(10 \%)$ when considering the requirement of high flexural strength and high brittle-resistance. Slag was a significant factor affecting the compressive-flexural ratio, and it also played an important impact on the flexural strength. Therefore, based on the requirement of high flexural strength and high compressive-flexural ratio, the best level of slag should be B3, which was $20 \%$ of the amount of cementitious material. When the content of silica fume was between $3 \%$ and $7 \%$, silica fume showed no significant effect on the $28 \mathrm{~d}$ flexural strength, and its effect on the compressive-flexural ratio was less significant or can be neglected. The optimum content of silica fume was selected as $\mathrm{C} 2$ (3\%) based on the high flexural strength at this content.

When the fly ash content was $20 \%$, the slag content was $20 \%$, and the silica fume content was $3 \%$, the $3 \mathrm{~d}$ compressive strengths and compressive-flexural ratios obtained smaller values. When the fly ash content was $10 \%$, the slag content was $10 \%$, and the silica fume content was $3 \%$, the $3 \mathrm{~d}$ flexural strength reached a larger value. When the fly ash content was $20 \%$, the slag content was $20 \%$, and the silica fume content was $1 \%$, the $28 \mathrm{~d}$ compressive strength and the compression ratio of the cement-based material get smaller values. When the fly ash content was $10 \%$, the slag content was $20 \%$, and the silica fume content was $3 \%$, the $28 \mathrm{~d}$ flexural strength obtained a larger value. According to the specific requirements in "Technical Specifications for Construction of Highway Cement Concrete Pavement" (JTG/T F30-2014), the amount of fly ash used in pavement concrete should not be more than $10 \%$. Therefore, A1B3C2 was regarded as the best selection, in which the mass ratio of various mineral admixtures in cement-based cementitious materials was fly ash: slag: silica fume $=10 \%: 20 \%: 3 \%$.

Table 7. Orthogonal test $28 d$ and range analysis.

\begin{tabular}{|c|c|c|c|c|c|c|c|c|c|}
\hline Number & $\mathbf{A}$ & B & $\mathbf{C}$ & \multicolumn{2}{|c|}{ D/Empty train } & \multicolumn{2}{|c|}{$\begin{array}{l}\text { Compressive } \\
\text { strength }\end{array}$} & $\begin{array}{l}\text { Flexural } \\
\text { strength }\end{array}$ & $\begin{array}{l}\text { Compressive- } \\
\text { Flexural ratio }\end{array}$ \\
\hline 1 & 1 & 1 & 1 & \multicolumn{2}{|l|}{1} & \multicolumn{2}{|c|}{50.9} & 9.68 & 5.26 \\
\hline 2 & 1 & 2 & 2 & \multicolumn{2}{|l|}{2} & \multicolumn{2}{|l|}{56.2} & 10.08 & 5.58 \\
\hline 3 & 1 & 3 & 3 & \multicolumn{2}{|l|}{3} & \multicolumn{2}{|l|}{55.7} & 10.31 & 5.40 \\
\hline 4 & 2 & 1 & 2 & \multicolumn{2}{|l|}{3} & \multicolumn{2}{|l|}{55.4} & 9.38 & 5.90 \\
\hline 5 & 2 & 2 & 3 & \multicolumn{2}{|l|}{1} & \multicolumn{2}{|l|}{53.7} & 9.38 & 5.72 \\
\hline 6 & 2 & 3 & 1 & \multicolumn{2}{|l|}{2} & \multicolumn{2}{|l|}{50.9} & 9.45 & 5.39 \\
\hline 8 & 3 & 2 & 1 & \multicolumn{2}{|l|}{3} & \multicolumn{2}{|l|}{50.2} & 9.49 & 5.29 \\
\hline 9 & 3 & 3 & 2 & \multicolumn{2}{|l|}{1} & \multicolumn{2}{|l|}{48.3} & 10.07 & 4.80 \\
\hline \multirow{6}{*}{$\begin{array}{l}\text { Compressive } \\
\text { strength }\end{array}$} & k1 & & 54.27 & \multicolumn{2}{|l|}{53.3} & 50.67 & 50.97 & & \\
\hline & $\mathrm{k} 2$ & & 53.34 & \multicolumn{2}{|l|}{53.37} & 53.30 & \multirow{2}{*}{$\begin{array}{l}53.60 \\
53.77\end{array}$} & & \\
\hline & k3 & & 50.74 & \multicolumn{2}{|l|}{51.63} & 54.37 & & & \\
\hline & $\mathrm{R}$ & & 3.53 & \multicolumn{2}{|l|}{1.74} & 3.7 & 2.8 & & \\
\hline & Pri & d secondary order & $\mathrm{C}$ & A & & $\mathrm{D}$ & B & & \\
\hline & Exc & evel & A1 & B2 & & $\mathrm{C} 3$ & D3 & & \\
\hline & $\mathrm{k} 1$ & & 10.023 & 9.473 & 9.540 & 9.710 & & & \\
\hline & $\mathrm{k} 2$ & & 9.403 & 9.650 & 9.843 & 9.593 & & & \\
\hline & $\mathrm{k} 3$ & & 9.603 & 9.943 & 9.647 & 9.727 & & & \\
\hline Flexural strength & $\mathrm{R}$ & & 0.620 & 0.506 & 0.303 & 0.134 & & & \\
\hline & Pri & d secondary order & A & B & $\mathrm{C}$ & $\mathrm{D}$ & & & \\
\hline & Exc & evel & A1 & B3 & $\mathrm{C} 2$ & D3 & & & \\
\hline & Op & mbination2 & $\mathrm{A} 1 \mathrm{~B} 3 \mathrm{C} 2$ & & & & & & \\
\hline & $\mathrm{k} 1$ & & 5.413 & 5.657 & 5.313 & 5.260 & & & \\
\hline & $\mathrm{k} 2$ & & 5.670 & 5.530 & 5.427 & 5.593 & & & \\
\hline & k3 & & 5.300 & 5.197 & 5.643 & 5.530 & & & \\
\hline Compressive & $\mathrm{R}$ & & 0.370 & 0.460 & 0.330 & 0.333 & & & \\
\hline & Pri & d secondary order & B & A & $\mathrm{D}$ & $\mathrm{C}$ & & & \\
\hline & Exc & evel & A3 & B3 & $\mathrm{C} 1$ & D1 & & & \\
\hline & Op & mbination 2 & $\mathrm{~A} 3 \mathrm{~B} 3 \mathrm{C} 1$ & & & & & & \\
\hline
\end{tabular}




\subsection{Verification Test}

The optimal mix proportion obtained from the above orthogonal tests was used for test verification. In the optimal mixture, the contents of fly ash, slag, and fume were $10 \%$, $20 \%$, and $3 \%$ of the amount of cement. The PP fiber content was $1.6 \mathrm{~kg} / \mathrm{m}^{3}$. The test results are shown in Table 8 , in which
$\mathrm{JZ}$ is the control group, in which specimens were prepared without the addition of any admixture. B presents the mixture group which was incorporated with superplasticizer, and $\mathrm{E}$ is the test group with the addition of fly ash, slag, silica fume, and PP fiber.

Table 8. Cement mortar verification test.

\begin{tabular}{|c|c|c|c|c|c|c|c|c|c|c|c|c|}
\hline \multirow[t]{2}{*}{ No. } & \multirow[t]{2}{*}{ FA (\%) } & \multirow[t]{2}{*}{ Slag (\%) } & \multirow[t]{2}{*}{ Fume (\%) } & \multirow[t]{2}{*}{ Sp (\%) } & \multirow[t]{2}{*}{ Fiber $\left(\mathrm{kg} / \mathrm{m}^{3}\right)$} & \multirow[t]{2}{*}{ W-B ratio } & \multicolumn{2}{|c|}{$\begin{array}{l}\text { Compressive } \\
\text { (MPa) }\end{array}$} & \multicolumn{2}{|c|}{$\begin{array}{l}\text { Flexural } \\
\text { (MPa) }\end{array}$} & \multicolumn{2}{|c|}{$\begin{array}{l}\text { Compressive } \\
\text {-Flexural ratio }\end{array}$} \\
\hline & & & & & & & $3 \mathrm{~d}$ & $28 \mathrm{~d}$ & $3 \mathrm{~d}$ & $28 \mathrm{~d}$ & $3 \mathrm{~d}$ & $28 \mathrm{~d}$ \\
\hline $\mathrm{JZ}$ & 0 & 0 & 0 & 0 & 0 & 0.5 & 24.8 & 44.5 & 4.76 & 7.95 & 5.21 & 5.59 \\
\hline B & 0 & 0 & 0 & 0.45 & 0 & 0.39 & 38.5 & 55.69 & 5.58 & 8.96 & 6.9 & 6.21 \\
\hline E & 10 & 20 & 3 & 0.45 & 1.6 & 0.39 & 23.2 & 38.05 & 5.65 & 9.04 & 4.1 & 4.21 \\
\hline
\end{tabular}

It can be clearly observed that the $3 \mathrm{~d}$ flexural strength was $5.65 \mathrm{MPa}$ and the compressive-flexural ratio was 4.1 when the optimal ratio was selected. Compared to group ' $\mathrm{JZ}$ ', the compressive strength of group ' $\mathrm{E}$ ' was reduced by $6 \%$, the flexural strength increased by $19 \%$, and the compressive-flexural ratio was reduced by $21 \%$. Compared to group ' JZ', the compressive strength of group ' $\mathrm{B}$ ' increased by $55.2 \%$, the flexural strength increased by $17.2 \%$, and the compressive-flexural ratio increased by $32.6 \%$.

The 28-day flexural strength of group ' $\mathrm{E}$ ' was $9.04 \mathrm{MPa}$ and the compressive-flexural ratio was 4.21 under the optimal mix ratio. Compared with the reference group ('JZ'), the compressive strength in the group ' $\mathrm{E}$ ' was reduced by $14 \%$, the flexural strength increased by $13 \%$, and the compressive-flexural ratio was reduced by $24 \%$. Compared with the reference group ('JZ'), the compression strength of group ' $B$ ' increased by $25 \%$, the flexural strength increased by $12.7 \%$, and the compressive-flexural ratio increased by $10 \%$. Therefore, the influence of water-binder ratio on the compressive strength of cement mortar is far greater than the flexural strength. Adding composite materials into cement base can greatly reduce the brittleness of the material and greatly improve the flexural strength of cement-based materials.

Based on the test results, the mixture proportions in group ' $E$ ' could provide adequate flexural strength and compressive-flexural ratio. The dosage of superplasticizer should be appropriately added because of the performance enhancement.

\subsection{Microstructure Analysis of Cement Matrix}

Figure 5 is an SEM image of the cement matrix of group 'JZ'. As shown in Figure 5, the internal pores of the cement matrix are relatively large, and due to the autogenous shrinkage of the cement matrix during the cement hydration reaction, microcracks of different scales are generated. The microcracks in the cement matrix gradually expanded with the age, and eventually developed into macro-cracks, which affected the internal structure of the cement matrix, thus reducing the mechanical strength and the durability.
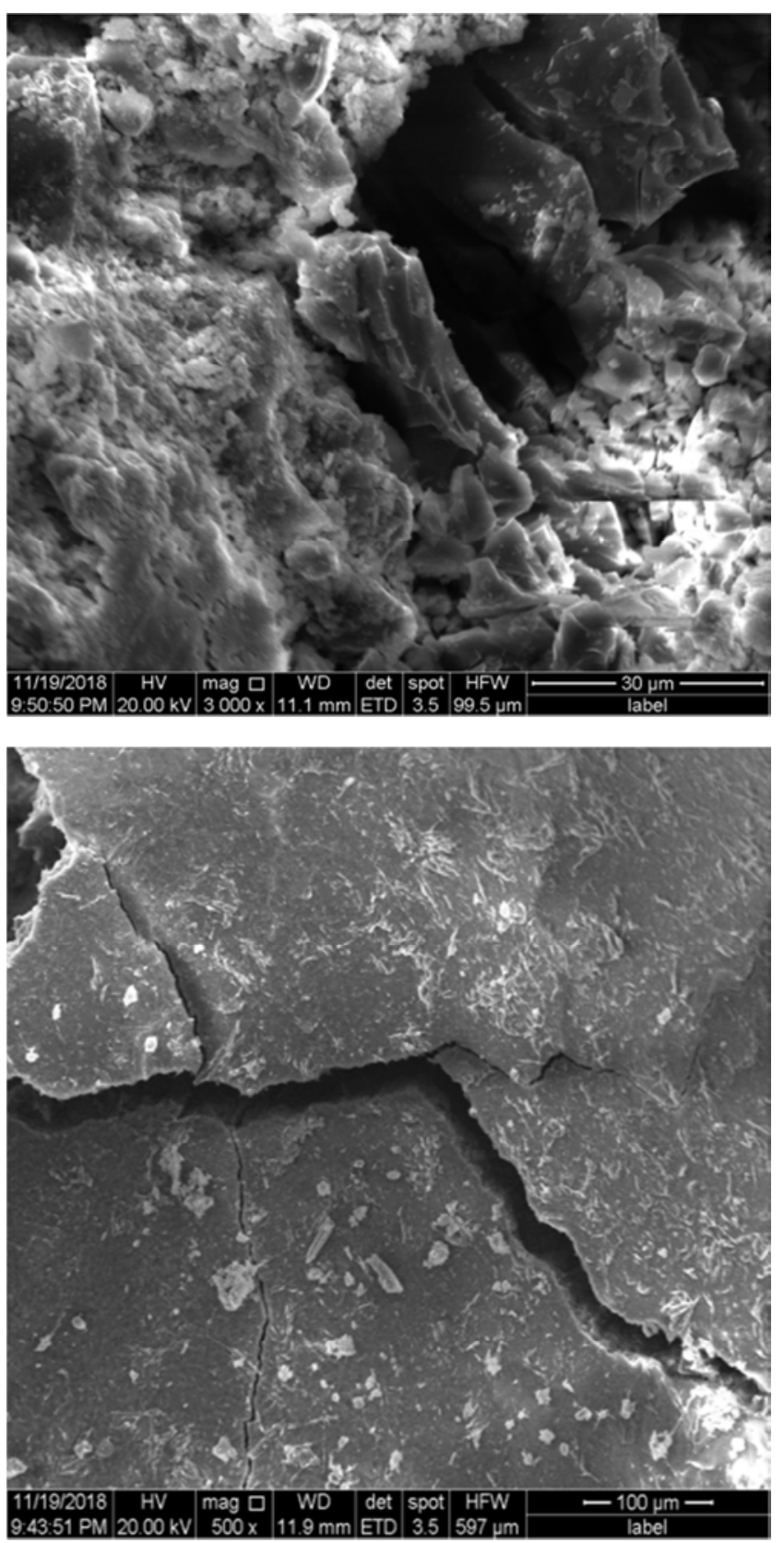

Figure 5. SEM image of group 'JZ'. 
Figure 6 is a cross-sectional structure image of a specimen mixed with mineral admixtures and PP fiber. It can be observed that a cement matrix with dense structure can be obtained by the addition of mineral admixture and PP fiber. Mineral admixtures are mixed into cement base because the particle sizes of fly ash, slag and silicon powder are different. Generally, the mineral admixtures which were used to partially replace cement are very fine and could reduce the void content and improve the pore size distribution, thus making the cement mortars denser. PP fiber in these mixtures could form the cross-linking structure, which enhanced the mechanical performance and the cracking-resistance. PP fiber also inhibited or delayed the generation and development of cracks.

By optimizing the proportion of mineral admixtures and reasonably distributing PP fibers in cement-based materials, cement-based materials with better mechanical properties and durability can be prepared.
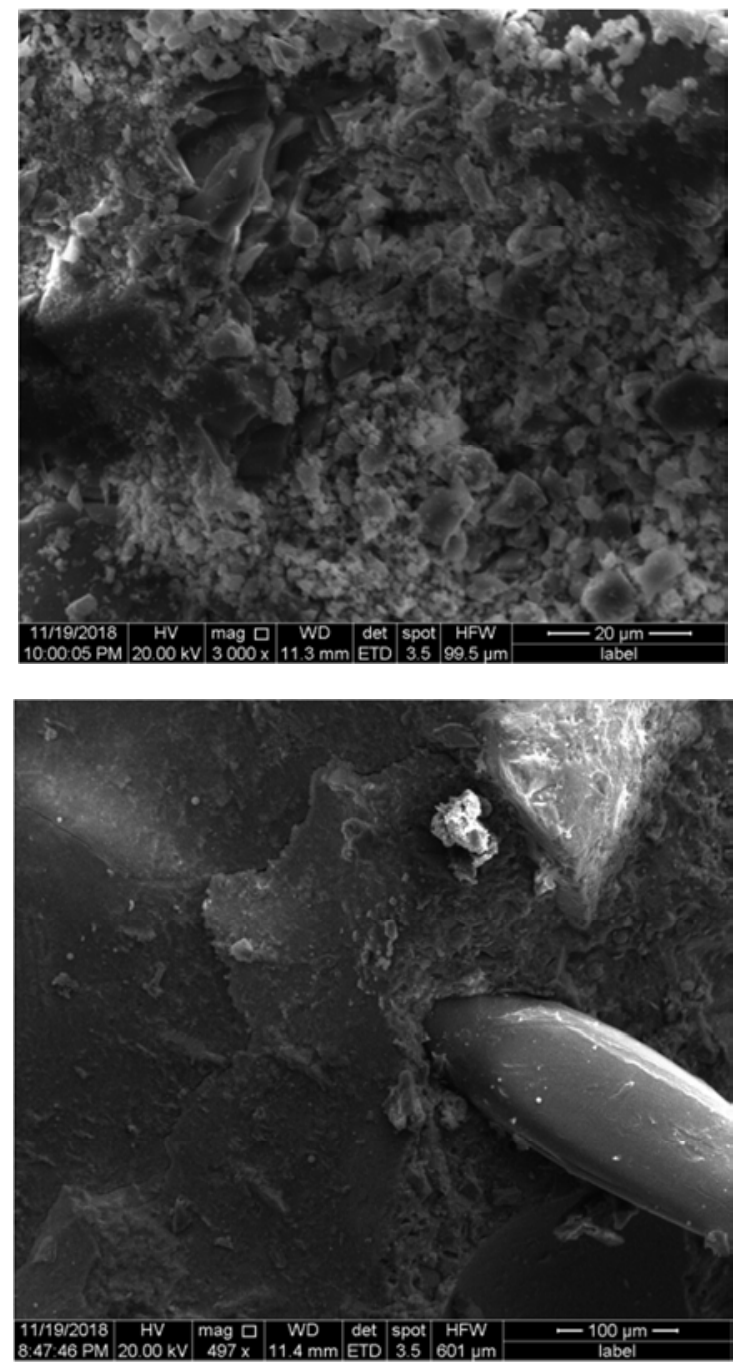

Figure 6. SEM image of test group.

\section{Conclusion}

A series of laboratory tests were conducted in this study to evaluate the effect of various mineral admixtures and PP fiber on the mechanical behaviors. Flexural strength and compressive-flexural ratio were selected to evaluate the brittle-resistance. Orthogonal tests were designed to determine the optimal mixture proportion, which could provide the superior brittle-resistance.

1) PP fiber could effectively improve the mechanical properties of cement-based materials and reduce the occurrence of microcracks. When the content of PP fiber was $1.6 \mathrm{~kg} / \mathrm{m} 3$, the brittleness of the specimens was the lowest, and the compressive strength was lower than the specimens without the addition of PP fiber. Considering the requirements of low brittleness and high flexural strength, the optimal dosage of PP fiber in cement matrix was $1.6 \mathrm{~kg} / \mathrm{m} 3$.

2) Orthogonal test method was employed to explore the optimal proportion of the cement mortars. The experimental results showed that the optimal proportion of mineral admixtures was: the dosage of fly ash, slag and silica fume was $10 \%, 20 \%$ and $3 \%$ of the content of cement respectively. The test results showed that the $3 \mathrm{~d}$ flexural strength of the cement-based composite was $19 \%$ higher than that of the reference mortar, the $3 \mathrm{~d}$ flexural strength was $21 \%$ lower, the $28 \mathrm{~d}$ flexural strength was $13 \%$ higher than that of the reference mortar, and the $3 \mathrm{~d}$ flexural strength is $24 \%$ lower than that of the reference mortar. The test results met the requirements of high flexural strength and low brittleness.

3) SEM technology was utilized to characterize the microstructure of the cement matrix, and the strength characteristics of the cement matrix with high flexural strength and low brittleness were preliminarily proved. The results showed that the addition of mineral admixtures and PP fibers can make the internal microstructure of the cement matrix denser.

\section{Acknowledgements}

This research was National Key R\&D Program of China, supported byHunan Provincial Science and Technology Department Key Project "Study on the Basic Theory of the Preparation of Green Ecological Concrete" (Project No.: 2013FJ2002).

\section{References}

[1] P. K. Mehta, P. J. M. Monteiro, Concrete: microstructure, properties, and materials, McGraw-Hill Publishing, New York, US, 2005.

[2] W. Song, J. Yin, Hybrid effect evaluation of steel fiber and carbon fiber on the performance of the fiber reinforced concrete, Materials 9 (8) (2016) 704.

[3] W. Sun, H. Yan, B. Zhan, Analysis of mechanism on water-reducing effect of fine ground slag, high-calcium fly ash, and low-calcium fly ash, Cement and Concrete Research 33 (8) (2003) 1119-1125. 
[4] R. K. Graham, B. Huang, X. Shu, E. G. Burdette, Laboratory evaluation of tensile strength and energy absorbing properties of cement mortar reinforced with micro- and meso-sized carbon fibers, Construction and Building Materials 44 (2013) 751-756.

[5] M. Leone, G. Centonze, D. Colonna, F. Micelli, M. J. C. Aiello, B. Materials, Fiber-reinforced concrete with low content of recycled steel fiber: Shear behaviour, 161 (2018) 141-155.

[6] V. Afroughsabet, L. Biolzi, T. J. J. o. m. s. Ozbakkaloglu, High-performance fiber-reinforced concrete: a review, 51 (14) (2016) 6517-6551.

[7] D. A. Hensher, Fiber-reinforced-plastic (FRP) reinforcement for concrete structures: properties and applications, Elsevier2016.

[8] W. Song, J. Yi, H. Wu, X. He, Q. Song, J. Yin, Effect of carbon fiber on mechanical properties and dimensional stability of concrete incorporated with granulated-blast furnace slag, Journal of Cleaner Production 238 (2019) 117819.

[9] J. Gao, A. Sha, Z. Wang, L. Hu, D. Yun, Z. Liu, Y. Huang, Characterization of carbon fiber distribution in cement-based composites by Computed Tomography, Construction and Building Materials 177 (2018) 134-147.

[10] G. M. Kim, H. Yoon, H. K. Lee, Autogenous shrinkage and electrical characteristics of cement pastes and mortars with carbon nanotube and carbon fiber, Construction and Building Materials 177 (2018) 428-435.

[11] A. Sassani, H. Ceylan, S. Kim, K. Gopalakrishnan, A. Arabzadeh, P. Taylor, Influence of mix design variables on engineering properties of carbon fiber-modified electrically conductive concrete, Construction and Building Materials 152 (2017) 168-181.
[12] Statista,

https://www.statista.com/statistics/219343/cement-productionworldwide/, 2016.

[13] C. D. Atiş, High-volume fly ash concrete with high strength and low drying shrinkage, Journal of materials in civil engineering 15 (2) (2003) 153-156.

[14] C. D. Atiş, A. Kilic, U. K. Sevim, Strength and shrinkage properties of mortar containing a nonstandard high-calcium fly ash, Cement and concrete Research 34 (1) (2004) 99-102.

[15] S. A. Bernal, R. M. De Gutierrez, A. L. Pedraza, J. L. Provis, E. D. Rodriguez, S. Delvasto, Effect of binder content on the performance of alkali-activated slag concretes, Cement and Concret Research 41 (1) (2011) 1-8.

[16] B. Bharatkumar, B. Raghuprasad, D. Ramachandramurthy, R. Narayanan, S. Gopalakrishnan, Effect of fly ash and slag on the fracture characteristics of high performance concrete, Materials and Structures 38 (1) (2005) 63-72.

[17] P. S. Deb, P. Nath, P. K. Sarker, The effects of ground granulated blast-furnace slag blending with fly ash and activator content on the workability and strength properties of geopolymer concrete cured at ambient temperature, Materials \& Design 62 (2014) 32-39.

[18] S. C. Kou, C. S. Poon, D. Chan, Influence of fly ash as a cement addition on the hardened properties of recycled aggregate concrete, Materials and Structures 41 (7) (2008) 1191-1201.

[19] K. Kuder, D. Lehman, J. Berman, G. Hannesson, R. Shogren, Mechanical properties of self consolidating concrete blended with high volumes of fly ash and slag, Construction and Building Materials 34 (2012) 285-295. 